\title{
RITMO Y CINEMA
}

\author{
Ángel Luis Hueso Montón \\ Universidade de Santiago de Compostela
}

Carlos Velo ${ }^{1}$, cineasta de origen gallego pero profundamente vinculado con la cinematografía mejicana debido a su exilio al finalizar la Guerra Civil, ocupa un lugar resaltable en la historia del cine gracias a una serie de contribuciones que mantienen su singularidad en el conjunto de este medio expresivo.

Por una parte, hay que recordar su aportación al cine documental español de los años treinta. Son años de una especial importancia para esta corriente cinematográfica a nivel mundial, puesto que encontramos ejemplos tan señeros y que han permanecido por encima del paso del tiempo, como la escuelas británica liderada por John Grierson, las diferentes corrientes que afloraron en los años de la depresión estadounidense (con cineastas como Pare Lorentz, Paul Strand y Leo Hurwit), el impulso realizado por el nacionalsocialismo alemán ejemplificado en la figura de Leni Riefensthal o las contribuciones de cineasta individuales como Luis Buñuel o Joris Ivens, ejemplos todos ellos que se han convertido en testimonios ineludibles para comprender la importancia del documental en el siglo pasado.

Dentro de este contexto es fácil de comprender que también en España se plasmara la preocupación por este tipo de cine; junto al hecho singular de Las Hurdes. Tierra sin pan (Luis Buñuel, 1932), son significativas las aportaciones que realizaron dos cineastas que trabajaron en colaboración, el mismo Carlos Velo y Fernando Gutiérrez Mantilla; obras como Almadrabas (1934), Infinitos, Felipe II y El Escorial y Tarragona (Tarraco Augusta) las tres rodadas en 1935, nos ofrecieron testimonios no sólo de sensibilidad, abordando temas de diferente entidad y temática, desde el documental social y etnográfico sobre la pesca del atún y que recuerda a grandes autores como Flaherty o Grierson, hasta la crítica política de la historia filipina y su visión de la piedra como eje del monumento escurialense pasando por la experimentación temática y estética de Infinitos. A ellos le seguirían al año siguiente Castillos de Castilla (junto con Mantilla) y, ya en solitario, Galicia (conocido también como Finis Terrae). ${ }^{2}$

Si siempre se le ha recordado por estas aportaciones documentales, no es menos importante su contribución al cine mejicano con obras que merecieron una reflexión por parte de la crítica y los historiadores. Fundamentalmente podemos recordar dos filmes en los que utilizó las imágenes con una especial maestría, como son Torero (1956) y Pedro Páramo (1966); si la primera, en la que recupera su dominio del documental, está reconocida como una de las mejores películas dedicadas al mundo de los toros, poniendo de manifiesto la riqueza humana de sus protagonistas y la presencia del miedo como un componente de su vida, la segunda es una de las más representativas adaptaciones de la literatura sudamericana llevando a las imágenes la fuerza descriptiva de Juan Rulfo y la imaginación en el entrecruzamiento de las vidas de sus protagonistas.

Pero junto a ello hay otro aspecto de la vida de Carlos Velo que nos interesa recordar de cara a interpretar el texto que tenemos entre manos. 
Es llamativa su formación académica, volcada sobre las ciencias naturales y en concreto la biología, la cual le llevó a realizar su licenciatura (1932), a trabajar los años siguientes como profesor auxiliar de la Cátedra de Entomología y como profesor de Historia Natural y Nociones de Física y Química en el Instituto de Enseñanza Media "Lagasca" de Madrid, y, finalmente, a defender su tesis doctoral en la Universidad de Madrid, la cual fue rechazada en primera instancia y posteriormente aprobada al presentarse con el apoyo de una película sobre las costumbres sociales de las abejas y la actuación de la abeja reina. $^{3}$

Carlos Velo volverá a retomar esta perspectiva académica y docente en los primeros años de su exilio mejicano, puesto que desde 1940 hasta 1944 impartirá clases de Zoología General y Sistemática, Ecología y Biogeografía todas ellas en el Instituto Politécnico Nacional; también en esos mismos años fue profesor de Artes Plásticas y Psicofísica del Cine en la Universidad de San Nicolás de Hidalgo, en Morelia. ${ }^{4}$

Una más exacta comprensión del texto que merece nuestra atención nos impulsa a recordar que el período de entreguerras posee una alta singularidad a nivel de reflexión sobre el sentido técnico y estético del cine; las consideraciones de teóricos como Sergei M. Eisenstein, Bela Balazs, Rudolph Arnheim, Walter Benjamin o Jean Epstein, son seguidas en todos los países por multitud de artistas, filósofos, literatos y, sobre todo, cineastas que se plantean el sentido de las imágenes animadas y sus posibilidades expresivas.

Con estas coordenadas podemos acercarnos al texto que Carlos Velo publica en el año 1940; recién llegado a Méjico inserta el que será su primer artículo en el segundo número de la revista Romance $^{5}$ aparecido el 15 de febrero de aquel año. Los planteamientos culturales de la revista, buscando la incorporación de una amplia diversidad de temas, hace posible que el cine y sus peculiaridades tenga cabida en sus páginas, lo cual se constató con los artículos que se le dedican (preferentemente firmados por Juan Gil-Albert) y en los que se recogen críticas sobre estrenos del momento y algunas reflexiones teóricas sobre la imagen. ${ }^{6}$ Velo insertó otra colaboración en la revista que bajo el título Símbolos en plata se incluyó en el número 4 del 15 de marzo de 1940.

Ritmo y Cinema es el título que encabeza el artículo de Velo. No puede sorprendernos que un hombre apasionado por el documental, aspecto de la imagen animada donde el montaje adquiere una especial singularidad, dedique su atención a reflexionar sobre la importancia y consecuencias que puede tener el ritmo en esa propia imagen; su admiración por los clásicos soviéticos ${ }^{7}$, el equilibrio que se busca entre el espacio y el tiempo para alcanzar ese concepto difícilmente definible pero fácilmente perceptible que es el ritmo, lo encontramos plasmado en las palabras y razonamientos que utiliza para hacérnoslo más asequible.

El artículo se inicia con una serie de párrafos introductorios, pero altamente significativos, en los que Velo construye el soporte de su argumentación. Empieza reivindicando que el cine no es un mero registro, ni una simple reproducción de aquello que se sitúa delante del objetivo; por el contrario, sugiere que el cine realiza una manipulación de lo meramente objetivo merced a la integración de aquellos elementos subjetivos que responden a la inspiración del cineasta, y los elementos derivados de la técnica que, ineludiblemente, deben estar presentes.

Pero da un paso más y defiende que es imposible que una técnica en sí misma, sin un apoyo estético que la enriquezca, pueda producir una obra de arte, pues antes al contrario, esa es la causa de la imperfección de aquellos filmes que se reducen a una técnica fría, basada en el virtuosismo pero falta de inspiración (aspecto que recuerda reflexiones similares en todos los ámbitos artísticos). Es la que el autor denomina como "técnica instrumental", que a pesar de su ajuste y corrección, no llega a trasmitir al espectador ningún tipo de emoción. ${ }^{8}$

Frente a ello defiende la "técnica expresiva", resultado de la integración de todos los elementos icónicos y sonoros hasta conseguir, con el montaje final, trasmitir una vivencia artística al espectador.

Culmina esta argumentación inicial (fundamental para entender todos los razonamientos posteriores) reivindicando la complejidad del 
cine puesto que en él se unen elementos espaciales y temporales, de forma que si los primeros se basan en la interpretación de los factores derivados del uso de la luz, los segundos inciden sobre el desarrollo temporal de los mismos, dando como resultado, y utilizando las propias palabras de Velo, que "esta doble maniobra, en la continuidad espacial de la pantalla y la discontinuidad del tiempo de permanencia de los planos durante la proyección, plantea el embrollado problema del ritmo cinematográfico".

A fin de abordar este complicado aspecto de la estética cinematográfica con la suficiente profundidad y, sobre todo, para comprender su complejidad de una forma lógica, Velo desdeña, en primer lugar, una interpretación simple y elemental como era la planteada por Ducom ${ }^{9}$ preconizando una mayor agilidad en el cambio de decorados y la reducción temporal de las secuencias. Sin embargo, es interesante destacar que este pionero francés concede importancia al uso del tiempo, considerándolo desde diferentes perspectivas en relación a la imagen. ${ }^{10}$

Frente a ello nuestro autor realiza una serie de reflexiones sobre cómo ha sido abordado este tema en otros ámbitos artísticos, de manera que posteriormente pueda realizar una trasposición de esos elementos al campo de la imagen animada.

Llama la atención que, en primer lugar, recuerde las definiciones dadas por dos teóricos de campos diferentes pero inspiradas ambas en filósofos griegos; será en primer lugar Francis Warrain el que recuerde a Aristógenes de Tarento al afirmar que "una serie de fenómenos que se producen con intervalos de duración, variables o no, pero regulados por una ley, constituye un ritmo". ${ }^{11}$ Le seguirá D'Eichtall (sic) que sobre la pauta de Platón dirá que "el ritmo es en el tiempo lo que la simetría en el espacio". ${ }^{12}$ Es de gran interés la mención que se hace en ambos casos a los aspectos relativos al espacio y el tiempo, elementos fundamentales para poder comprender lo que es la dinámica interna de lo que denominamos como "imagen en movimiento".

A partir de ahí realiza un paso adelante y presta atención a los razonamientos desarrollados por una serie de matemáticos y arquitectos que establecieron relaciones entre la geometría, las matemáticas y el mundo de las artes plásticas, y especialmente la arquitectura.

La atención preferente se centra en las clasificaciones que Ghyka ${ }^{13}$ realiza en relación a los ritmos artísticos, resaltando las cadencias y sus repeticiones de forma más o menos pautada o, en ocasiones, sin mantener una repetición que pueda ser interpretada como tal. Es interesante cómo Ghyka matiza la utilización terminológica al diferenciar los aspectos temporales y los espaciales, explicitándolo cuando dice: "La palabra ritmo debería reservarse para lo que caracteriza la periodicidad de los acontecimientos en el tiempo, aplicándose la simetría (encadenamiento de las conmensurabilidades entre las diferentes partes y entre estas partes y el todo) a las relaciones mutuas de los elementos y del conjunto en una sucesión espacial". ${ }^{14}$

Es interesante la forma en que Carlos Velo realiza una interpretación de estas clasificaciones y las reconduce hacia el campo del cine (sobre todo teniendo en cuenta que nos encontramos ante una proyección) y, por ello, hace hincapié en la interrelación de tres tipos de ritmos, los visuales, los auditivos y los del tiempo. Sin embargo, es necesario apuntar una cierta confusión conceptual entre los aparatos que soportan estos ritmos (pantalla, altavoz, montaje) y sus características intrínsecas, pues lo que se está planteando es la trilogía formada por el ritmo dentro del cuadro (aquellos elementos que entran a formar parte de la imagen, entre los que destaca la perspectiva), los acústicos derivados de la incorporación del sonido y aquel otro que se genera por el tipo de montaje que realicemos con el conjunto de las imágenes.

Quizás la aportación más interesante que se deriva de las reflexiones de Ghyka sea la interrelación entre los aspectos espaciales y los temporales, dos elementos que todos los teóricos del cine han considerado como fundamentales para entender el concepto de movimiento y su aplicación a las imágenes cinematográficas.

Completa la aproximación a teóricos que han trabajado sobre el ritmo, recordando las aportaciones de Moesse ${ }^{15}$ que a través de las mediciones de edificios egipcios, griegos y medievales llegó a constatar la importancia de la orientación cardinal de las edificaciones a lo que 
venía a unirse la proyección de determinadas figuras (fundamentalmente tetraedro, cubo, octaedro, icosaedro y dodecaedro) y su vinculación con el número áureo. ${ }^{16}$

Desde otra perspectiva (a través del estudio de las formas de los vasos griegos y sus relaciones con el rectángulo dinámico) se sitúan las reflexiones de Jay Hambidge ${ }^{17}$; la importancia que confiere a la simetría ("It is impossible to introduce rhythm into design composition without first introducing symmetry") y su interrelación con figuras que parecen presididas por proporciones más convencionales, le permite establecer la existencia de un módulo de acuerdo con el cual se produce el desarrollo de todos los elementos tanto estructurales como decorativos.

La parte final del artículo incide de manera radical en la trasposición de estas reflexiones del ámbito artístico al cinematográfico. Carlos Velo nos recuerda la importancia de determinados aspectos técnicos (y su resultado artístico) como elementos que entran a formar parte de un film; es significativa la importancia que concede a los aspectos sonoros, puesto que si por una parte resalta la fuerza del movimiento de la cámara para acentuar el ritmo visual, por otra, enumera elementos sonoros como son la palabra, la inflexión de la frase dicha, los ruidos y el mismo silencio (recordando la secuencia memorable de la habitación del albergue en La reina Cristina de Suecia, Queen Christina, Rouben Mamoulian, 1933) que forman un todo de indudable repercusión sobre el resultado final del film.

Nos recuerda que el ensamblaje de los elementos visuales y sonoros por medio del montaje dio origen a diferentes posturas por parte algunos destacados cineastas, como son los de Eisenstein y el contrapunto, la consideración de la imagen por encima del sonido por Chaplin o la búsqueda de una belleza por encima del realismo en el caso de Ruttmann.

Estas reflexiones las podemos entender como deudoras de la trasformación que ha ex- perimentado la imagen animada en la década inmediatamente anterior (y en la cual Velo inició su trayectoria cinematográfica); el impacto de la incorporación del sonido abrió una serie de reflexiones que no se limitaron a los ejemplos citados anteriormente, sino que obligaron a todos los cineastas a profundizar en la manera de utilizar estas diferentes aportaciones y, sobre todo, integrarlas en un resultado que fuera coherente desde los puntos de vista técnicos, narrativos y estéticos.

Todo ello se conjuga en el montaje con su diversidad de recursos (de acuerdo con los planteamientos de cada género o tipo de película), buscando la continuidad de la historia como factor determinante y el sentido que le pueda conferir el realizador con su sensibilidad personal; de alguna manera estamos hablando de una forma de entender el cine que se consagró en esos años y que hemos dado en denominar como "clasicismo cinematográfico".

Velo resume estos planteamientos en una frase que va más allá de lo poético, al expresar: "Cuando los elementos visuales -belleza plástica del fotograma- y los auditivos -ritmo paralelo de sonidos- son proporcionales, eurítmicos, armónicos y la medida de los planos sigue una pulsación o ritmo adecuado al tema, el espectador cae en el "encantamiento estético".

Como consideración global y última sobre este interesante texto, debemos resaltar que su localización a principios de los cuarenta pone de manifiesto la importancia que tuvieron las reflexiones sobre la imagen animada en los años inmediatamente anteriores, la profundidad de los argumentos expuestos por Carlos Velo yendo más allá de lo meramente cinematográfico para buscar las raíces estéticas que pueden enriquecer la interpretación de las imágenes en movimiento, y la necesidad de establecer una valoración global de las mismas por encima de las aportaciones individuales de sus elementos integrantes. 


\section{NOTAS}

1 Carlos Velo (Cartelle, Ourense, 15 de noviembre 1909- México D.F., 1 de marzo 1988) posee una trayectoria personal y profesional muy sugestiva. Para su conocimiento son imprescindibles las obras de Miguel Anxo Fernández: Carlos Velo. Cine e exilio. Vigo, Promocións Culturais Galegas, 1996 y As imaxes de Carlos Velo. Vigo, Promocións Culturais Galegas, 2002 (Premio "Sempre en Galiza de Ensaio 2001").

${ }^{2}$ Miguel Anxo Fernández: Carlos Velo, documentalista, en Josep Catalá, Josetxo Cerdán y Casimiro Torreiro (coords.): Imagen, memoria y fascinación. Notas sobre el documental en España. Madrid, Ocho y Medio, 2001, 167-178 y Fernando Redondo Neira: Carlos Velo. Itinerarios do documental nos anos trinta. A Coruña, Xunta de Galicia-Festival de Cine de Ourense, 2004.

3 Fernández: Carlos Velo. Cine y exilio, págs. 18-19.

${ }^{4}$ Fernández: As imaxes de Carlos Velo, pág. 91.

${ }^{5}$ La revista Romance. Revista Popular Hispanoamericana se publicó en Méjico desde 1040 a 1941 y se planteó con el deseo de fundir la trayectoria cultural española perpetuada en los exiliados y la cultura hispanoamericana. Véase Teresa Férriz Roure: Romance, una revista del exilio en Méjico. Sada, A Coruña, Edicións do Castro, 2003. 39-40.

6 Férriz Roure: Ob. Cit., pags.

7 "Eisenstein es la ciencia, la arquitectura, la frialdad; Dovjenko es la ternura, la otra dimensión que el científico necesita" (Juan Hernández Les: Carlos
Velo, un rezagado del exilio, "Cinema 2002", n 32 (octubre 1977), págs.. 42-45.

8 Podemos recordar que planteamientos similares se han producido de forma reiterada a lo largo de la historia del cine, desde el "caligrafismo" del cine fascista o el "cinéma de qualité" atacado por los críticos-directores de la Nueva Ola francesa, hasta los peligros apuntados en relación a determinado cine de las últimas décadas en el que la riqueza de los medios técnicos y de los efectos especiales basados en imágenes digitales busca sorprender al espectador pero nunca emocionarle.

9 Jacques Ducom: Le cinematographe scientifique et industriel. Traité pratique de cinematographie. París, L. Geisler editeur, 1911. Se trata de un conocido fotógrafo que el 19 de julio de 1885, junto con Gaston Tissadier, sobrevoló París en un globo y realizó siete fotografías; aunque no eran las primeras fotografías aéreas de París, sí que tuvieron una gran difusión, sobre todo la del "Puente de la isla de San Luis", en Robert Doty: After... with Balloon and Camera. "Cast Off" was the Command for the First Aerial Photographs, "Image. Journal of Photography and Motion Pictures of the George Eastman House", $n^{\circ} 65$ (november 1958), págs. 195-210 (en concreto 195, 205 y 207)

10 "L'operateur intelligent et artiste sentira tout de suite s'il se trouve en deça ou au-delà de la vitesse à laquelle doit être projetée la vue. II n'aura donc qu'à régler son allure sur celle qui convient le mieux aux effets que la bande cherche à donner. II arrivera même que, dans une même bande, il faillé changer de vitesse plusieurs fois". Ducom: Ob. Cit., pág. 296, citado por Georges Sadoul: Early Film Production in England. The Origin of Montage, Close-ups, and Chase Sequence, "Hollywood Quarterly", vol. 1, n 3 (april 1946), 249-259.

${ }^{11}$ Francis Warrain: L'espace. París, Librairie Fischbader, 1907.

12 Eugéne D'Eichthal: Du rythme dans la versification française. París, Lemerre, 1892.

${ }^{13}$ Matila C. Ghyka, hombre polifacético que dedicó una gran atención a los estudios matemáticos y su implicación con el mundo artístico y estético. Entre sus obras más interesantes hay que destacar Estética de las proporciones en la naturaleza y en las artes. Barcelona, Editorial Poseidón, 1979 (1 ${ }^{a}$ edición 1927), El número de oro. Ritos y ritmos pitagóricos en el desarrollo de la civilización occidental. I Los ritmos. II Los ritos. Barcelona, Editorial Poseidón, 1978 (1 ${ }^{a}$ edición 1931) y Ensayo sobre el ritmo. Barcelona, Editorial Poseidón, 1978 (1ª edición 1938)

${ }^{14}$ Ghyka: El número de oro, t. I, pág. 145.

${ }^{15}$ Ernst Moessel: Die Proportion in Antiche und Mittelalter. München, C. H. Beck, 1926

${ }^{16}$ María Cecilia Tomasini: El número y lo sagrado en el arte. Segunda parte, "C\&T. Revista de Ciencia y Tecnología" (Universidad de Palermo), 2003, págs. 53-70 (en concreto, págs. 64-65).

17 Jay Hambidge: Practical Applications of Dynamic Symmetry. New York, The Devin-Adair Company, $1960\left(1^{\text {a }}\right.$ edición 1932). 